\title{
The Impact of Behavioral ENGAgement on Outcomes in Graduate Business BlENDED LEARNING ENVIRONMENTS
}

\author{
Stephanie R. Nesbitt, Matthew D. Marmet, \\ Tracy M. Balduzzi, and Rick Fenner
}

Stephanie R. Nesbitt (srnesbit@utica.edu) is an Assistant Professor at Utica College. Matthew D. Marmet (mdmarmet@utica.edu) is Education Experience Coordinator for MBA programs at Utica College. Tracy M. Balduzzi (tmbalduzzi@utica.edu) is Director, Graduate Program Operations at Utica College. Rick Fenner (rfenner@utica.edu) is Interim Dean of the School of Business and Justice Studies at Utica College. Utica College is located at 1600 Burrstone Road, Utica, NY 13502. Correspondence concerning this paper should be addressed to Stephanie R. Nesbitt.

\begin{abstract}
Blended learning seeks to address several common problems that exist in higher education online learning models. Often, these models attempt to reproduce traditional classroom models which focus on students acquiring knowledge from a single subject matter authority. This traditional model does little to foster students' engagement in the learning process, and a significant body of
\end{abstract}


research indicates that the importance of such engagement, regardless of how it is defined, cannot be overstated.

Given its demonstrated importance to academic success, the ability to measure student engagement becomes essential. Interestingly, much of the research in this area has employed instructor-rated or student self-rated measures of engagement. In this study we examine how student behavioral engagement impacts learning outcomes in blended learning environments by using attendance as a proxy measure for engagement.

Working from the hypothesis that student engagement (behavioral) would have a positive impact on student success in graduate business education (as measured by final course grades), our results demonstrate a relationship in the expected directed between student engagement and the students' final grades in the classes.

Keywords: engagement, blended learning, distance education, student success, graduate business education

DOI: http://dx.doi.org/10.15239/j.brcacadje.2018.07.01.ja04

\section{INTRODUCTION}

With a shift toward online learning, need for increased enrollment, and focus on student retention and satisfaction, many universities are using delivery methods that combine the social interactions and network development of traditional classroom learning with the flexibility and diversity of online learning into a blended model of education. The term "blended learning" for the purpose of this research is "a learning program where more than one delivery mode is being used with the objective of optimizing the learning outcome and cost of program delivery" (Singh \& Reed, 2001, p. 1). The blended MBA program for this research incorporated thoughtful integration of face-to-face and online instruction, blending the best features of classroom interaction with live instruction to deliver 
a personalized experience. Walker and Keeffe (2010), authors of "Selfdetermined Blended Learning: A Case Study of Blended Learning Design" found that blended learning allows colleges and universities to adhere to community and professional standards while addressing the students' need for flexibility.

Simply, blended programs attempt to dismantle the ideas that many still have of online education, such as

"Online interaction has shown too many drawbacks compared to face-to-face interactions: Non-verbal communication cannot be conveyed using online media, and the efficacy/efficiency of offline groups is still much higher than online groups" (Anderson, Boyes, \& Rainie, 2012, p. 20).

Blended learning attempts to avoid many of the mistakes made in higher education, in which "many online learning environments seek to replicate traditional classroom instruction by focusing on knowledge acquisition through a single knowledge authority (i.e., the instructor) and are not particularly supportive of student engagement" (Revere \& Kovack, 2011, p. 114).

Essentially using a blended approach of live and recorded classroom sessions, with the flexibility of choosing modality and online resources, has the potential to revolutionize modern education and further explore and develop upon the concepts of learning communities and student engagement.

In this study we examine how student behavioral engagement impacts learning outcomes in blended learning environments by using attendance as a proxy measure for engagement.

\section{LITERATURE REVIEW}

Student engagement has received a great deal of attention in the literature since the mid-1990s. Although past researchers have defined it in several 
different ways (Trowler, 2010), the current study employs the following definition: "The time and effort students devote to activities that are empirically linked to desired outcomes of college and what institutions do to induce students to participate in these activities" (Kuh, 2009, p. 683). Given the importance of, and emphasis placed on, the development of the social and learning networkin the blended MBA program, the authors felt that any definition of student engagement lacking mention of efforts made on the institutional side would be inadequate.

In addition to this overarching definition, prior researchers have carved student engagement into three distinct dimensions. Fredricks, Blumenfeld, and Paris (2004) identify these dimensions as behavioral, emotional, and cognitive engagement. Behaviorally engaged students typically comply with behavioral norms of education such as attending class and being actively involved in their courses. Emotional engagement deals with students' levels of interest, boredom, and happiness as they relate to their education. Students who are cognitively engaged are invested in their work, and seek to gain a high level of mastery of their learning material (Fredricks, Blumenfeld, \& Paris, 2004). Although their importance should not be overlooked, it should be noted here that a thorough investigation of the emotional and cognitive dimensions of student engagement is beyond the scope of this study. The focus instead will be on the behavioral dimension alone, and a discussion of the rationale behind this (based on available data), and how the authors believe this contributes fairly uniquely to the literature will follow.

Behavioral engagement is most commonly defined in one of three ways (Fredricks, Blumenfeld, \& Paris, 2004). The first concerns positive conduct and student conformity to school norms, which can range from attending class to being polite once the student is within the classroom environment (Archambault, Jauosz, Morizot, \& Pagini, 2009). The second definition deals with involvement in learning and includes behaviors such as concentrated attention, initiation, persistence, and concerted effort (Gonido, Voulala, \& Kiosseoglou, 2009). Finally, the third definition 
relates to student involvement in extracurricular activities such as sports and school governance (Fredricks, Blumenfeld, \& Paris, 2004).

The importance of such engagement, regardless of how it is defined, cannot be overstated. Graham, Tripp, Seawright, and Joeckel (2007) indicate that "a diverse body of educational research has shown academic achievement is positively influenced by the amount of active participation in the learning process" (pp. 233-234). Echoing this, Kuh (2009) states that students who devote more time and energy gained more from their studies and other aspects of the college experience than those who do not.

\section{Measuring Engagement}

With its demonstrated importance to academic success, the ability to measure behavioral engagement becomes critical. Interestingly, much research on this dimension of engagement has employed teacher ratings of students and self-report surveys to capture it (Fredricks, Blumenfeld, \& Paris, 2004). A potential concern with this method of data collection deals with the issue of self-presentation. Due to the social desirability bias, survey respondents tend to underreport socially undesirable activities and over report socially desirable ones (Krumpal, 2013). Although one's own levels of behavioral engagement may not be as taboo to report on as things like racism or sexual activity, it is cast in a very positive light and does possess a positive connotation. Therefore, when being asked to respond to questions designed to assess their levels of it, students may feel the pressure of the aforementioned self-presentation concerns, and provide answers that generate inaccurate survey estimates.

Another concern with this type of collection method is survey fatigue. Adams and Umbach (2012) refer to this as over-surveying and survey saturation, and view it as a potential problem with surveys given in an educational environment. In general, surveys are everywhere. People are exposed to them after receiving some sort of service, while on the internet, and at the end of a shopping experience (Adams \& Umbach, 2012). Students who are constantly being surveyed (both inside and outside of school) may develop feelings of ambivalence toward these measures, 
resulting in lower response rates and/or biased data. Subsequently, the external validity of such surveys could be called into question. The authors also indicate the timing of surveys may impact levels of fatigue. Surveys that immediately follow others are the most susceptible, introducing yet another variable to be weary of when surveying students (Adams \& Umbach, 2012).

Although the authors here are not trying to discredit prior survey research on behavioral engagement (and a discussion of its benefits and conveniences are beyond the realm of this study), we would like to offer a more objective measure of it, which taps into the first manner in which it is defined. Again, behavioral engagement can be characterized by activities such as attending one's classes (Archambault, et al., 2009). This is what Fredricks, Blumenfeld, and Paris (2004) refer to as a "conduct measure" (p. 65 ) of engagement. This measure of engagement can include positive behaviors like attending class, as well as "negative behaviors...which are indicative of disengagement, such as the frequency of absences and tardiness" (p. 65). In addition, the authors also assert that commitment is essential to the common understanding of the term engagement. Regarding attendance, one can easily see how this applies. Those who attend class at higher levels should be considered more committed, or more engaged. This too suggests that there may be different levels, or degrees of engagement along the behavioral dimension.

In a literature review on student engagement, Trowler (2010) expands on this and suggests that the behavioral dimension of engagement (along with the emotional and cognitive dimensions) can be thought of in terms of polarity. Trowler asserts that students can be behaviorally engaged in either a positive or negative way, with those performing at neither end of the spectrum considered not to be engaged at all. An example of a positively engaged student would be someone who attends lectures and participates with enthusiasm. Someone who is negatively engaged would actually boycott, picket, or disrupt the lectures, and a non-engaged person simply skips the lectures altogether (Trowler, 2010). This continuum of 
behavior once again raises the idea that there are differing levels of these conduct measures of engagement. The consequences of performing at certain levels will be discussed below.

\section{PREVIEW COMPLETE}

This completes the limited preview of this paper. Please visit the link below to purchase.

\section{Citation Information}

Nesbitt, Stephane, R., Matthew D. Marmet, Tracy M. Balduzzi, and Rick Fenner. "The Impact of Behavioral Engagement on Outcomes in Graduate Business Blended Learning Environments .” The BRC Academy fournal of Education 7, no. 1 (2018): 79-99. http://dx.doi.org/10.15239/ j.brcacadje.2018.07.01.ja04 